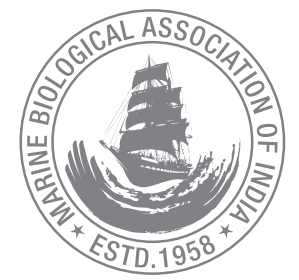

\title{
Climate change impact on the feeding habits of Indian mackerel observed along the Kerala coast
}

\author{
V. H. Sajna, P. U. Zacharia*, Liya V. Benjamin, G. Rojith and K. G. Mini \\ ICAR-Central Marine Fisheries Research Institute, Kochi- 682 018, Kerala, India. \\ *Correspondence e-mail: zachariapu@yahoo.com
}

Received: 26 Oct 2019 Accepted: 15 Dec 2019 Published: 25 Dec 2019

Original Article

\begin{abstract}
While most food and feeding research in fisheries emphasize the feeding habits and diet components of the fish, the aim of the present work was to assess any change in the diet composition of Indian mackerel Rastrelliger kanagurta (Cuvier, 1816) and identify the role of climate change in effecting it. Non-parametric statistical technique, the Generalized Additive Model (GAMs) was used for modeling the causal link of diet changes in relation to climate change using mgcv package of $R$ software. Monthly Index of Relative Importance (IRI) was calculated for 36 months from January 2013 to December 2015 and major prey items in the diet were identified. Climatic variables - Sea Surface Temperature (SST), precipitation (Pr), Chlorophyll a (Chl a), salinity and Ekman transport or coastal upwelling index (CUI)) pertaining to the study area were extracted for the period. Length-wise IRI was compared to check the existing patterns in the feeding habits of the fish. The dominant prey items observed in the gut of Indian mackerel during the study period were diatoms (Fragillaria sp., Nitzchia sp., Thalassiothrix sp., Thalassiosira sp. and Coscinodiscus sp.), dinoflagellates (Ceratium sp., Ornothocercus sp., Dinophysis sp. and Prorocentrum sp.), copepods (Calanoida, Cyclopoida and Harpacticoida), decapods (Acetes) and tintinnids (Tintinnopsis sp., Codenellopsis sp. and Flavella sp.). GAM models were fitted with monthly IRI of the major prey items (copepods, diatoms, dinoflagellates, Acetes and tintinnids) in the gut
\end{abstract}

and climatic variables. Model selection was done in terms of sharpening the relation between the predictors and the response variable using Akaike information criterion, R-squared and F-statistics. GAM model results revealed that occurrence of prey items in the diet of Indian mackerel were influenced by environmental variables. An increase in the relative importance of dinoflagellates, Acetes and tintintids in the diet over the historic period was observed. The study also revealed a shift in the diet composition of younger fishes. The results of the current study provide a more in-depth assessment of the nonlinear relationship between climatic variables and diet composition of Indian mackerel.

Keywords: climate change, diet composition, generalized additive model, Indian mackerel, index of relative importance, Kerala

\section{Introduction}

Climate change poses significant and long-term risks to fisheries in many tropical developing countries (IPCC, 2007). It will exacerbate existing physical, ecological, and socioeconomic stresses on marine fisheries sector. Climate change directly impacts the performance of individual organisms at various 
stages in their life history via changes in physiology, morphology and behavior. Understanding the extent of climate change impacts on ecosystems and their interactions are key requirements for informing policy debates on climate change and devising adaptive management responses (Harley et al., 2006).

India is one of the major fish producing countries in the world, contributing $6.03 \%$ of the global fish production. The Indian mackerel Rastrelliger kanagurta (Cuvier, 1816) is an important commercial fishery resource along the Kerala coast, contributing $8 \%$ to the annual marine fish landings of India in 2018 (CMFRI, 2018). It is a pelagic shoaling species with maximum abundance between $8^{\circ} \mathrm{N}$ and $12^{\circ} \mathrm{N}$ latitudes and $75^{\circ} \mathrm{E}$ and $77^{\circ} \mathrm{E}$ longitude in India, generally known as Malabar upwelling zone. The fish prefers to stay close to the thermocline (Abdussamad et al., 2010). The Indian mackerel is a filter feeder which feeds on plankton (Sivadas and Bhaskaran, 2009), and the main prey items include diatoms, dinoflagellates, algae, tintinnids and other zooplanktonic forms. Feeding habits of the young ones of mackerel indicates a carnivorous diet while in later stages it moves to a more planktivorous diet (Rao, 1964).

Diet analyses of fishes are of major importance in their biological studies. A good dataset of basic ecological parameters of the exploited marine resources is necessary for information, decision making and future management of a fishery resource. It can also be further used with appropriate fisheries models for understanding intra- and inter-species level interactions such as predation, competition and trophodynamics as well as construction of food webs. While many studies have been done on the food and feeding habits of mackerel, no attempt has been made to study feeding patterns in the recent years in the context of climate change. The purpose of this study was to examine change in the diet composition of mackerel in relation to climate change with reference to the already established feeding habits, making it a key study on climate change impacts in marine fisheries.

\section{Material and methods}

\section{Study area and sampling}

Samples of fresh Indian mackerel were taken from three major landing centres of Ernakulam District along the southern coast of Kerala - Cochin Fisheries Harbour, Munambam Fisheries Harbour and Kalamukku, during the period 2013 January to 2015 December. The fishes were brought to the lab, analysed for biological characters and the guts were removed and examined in fresh condition, to the extent possible. Further additional number of guts were preserved in 5\% formalin and examined later. Thirty-five guts were collected and examined in each month from all the centres and a total of 1,265 guts were examined during the entire period of study. The guts were classified into five major groups depending on the amount of food present, as trace (T), one-fourth full (OF), half full (HF), three-fourth full (TF) and full (F). The first and the second groups were considered as poorly fed (PF), third as moderately fed (MF) and fourth and fifth groups as actively fed (AF) groups.

\section{Diet composition}

After the gut weight and gut content weight were recorded, the contents were diluted to $10^{-1}$ dilution and examined under a compound microscope using a Sedgewick Rafter counting chamber. The gut contents were identified to their lowest taxonomic level under a compound microscope at 10X magnification and for more accurate identification, Phase contrast microscope and Stereomicroscope at 40X magnification for zooplanktons were also used. Prey composition patterns according to different seasons and fish lengths were estimated. Diet was described as:

Frequency of occurrence,

$$
\% O=\frac{J i}{\sum_{k}^{n} i=N} * 100
$$

Percentage by number,

$$
\% N=N i / \sum_{k=i}^{n} \quad N * 100 \quad--(2)
$$

Percentage by volume,

$$
\% V=\frac{V i}{\sum_{k=i}^{n} V} * 100
$$

where Ji was the number of guts with prey item i, $\sum \mathrm{N}_{\mathrm{i}-\mathrm{n}}$ is the total number of guts with food, $\mathrm{Ni}$ is the total number of prey item i in a gut and $\sum \mathrm{N}_{\mathrm{i}-\mathrm{n}}$ is the total number of prey (i-n) in the gut, $V i$ is the volume of prey item $i$ and $\sum V_{i-n}$ is the total volume of all prey items in the gut. To estimate the importance of various prey items in the gut, the Index of Relative Importance (IRI) was calculated (Pinkas et al., 1971). This index is an integration of measurement of number, volume and frequency of occurrence to assist in evaluating the relationship of the various food items found in the stomach. It was represented as percentage (\%IRI).

\section{Index of Relative Importance, \\ $\% I R I=(\% N+\% V) * \% O$}

An asymptote curve relating cumulative percentage of prey against percentage by number of guts examined was estimated to exhibit the surplus sample size. Feeding specialization of Indian mackerel was examined by Amundsen plot (Amundsen et al., 1996). Trophic level of the fish was also estimated (Pauly et al., 1998). 


\section{Climatic variables}

To understand temporal changes in the climatic and oceanographic variables off Kerala, monthly average data on sea surface temperature (SST), salinity, precipitation (Pr) and Chlorophyll a concentration ( $\mathrm{Chl} \mathrm{a}$ ) were downloaded for $8^{\circ}$ and $12^{\circ} \mathrm{N}$ latitudes and $75^{\circ}$ and $77^{\circ} \mathrm{E}$ longitudes for 2013-2015. The SST data was downloaded from the International Comprehensive Ocean-Atmosphere Data Set (ICOADS-NOAA) and Pr data was obtained from CPC Merged Analysis of precipitation dataset (COARDS- NOAA) for a resolution of $1^{0 *} 1^{0}$. Non log-transformed $\mathrm{Chl}$ a data from OCl (SeaDAS-NASA) for $4 \mathrm{~km}$ resolution and salinity from MIROC-ESM-CHEM model output prepared for CMIP5 historical were obtained. The Ekman mass transport derived from the alongshore wind stress for the study area was taken as an index of coastal upwelling (CUI). Monthly data for SST, Pr, Chl $a$ and Ekman transport for the period 2013 to 2015 were used to study the effect of environmental variables on the diet components of Indian mackerel.

\section{Statistical analysis}

Correlation matrix was plotted to find the relationship of climatic variables on the varying monthly percentage IRI of each prey item in the gut of Indian mackerel. The prey items were taken as independent variables and the environmental variables (SST, $\mathrm{Pr}$, salinity, $\mathrm{Chl} a$ and $\mathrm{CUI}$ ) as dependent variables.

The mgcv package in $\mathrm{R}$ (3.5.2) was used to fit a GAM model with prey composition (\%IRI) as response variables and environmental variables as covariates. Generalized Additive Models (Hastie and Tibshirani, 1990) are semi-parametric extensions of GLMs having an underlying assumption that the functions are additive and the components are smooth. A GAM, like a GLM, uses a link function to establish a relationship between the mean of the response variable and a "smoothed" function of the covariate (s). The general structure of GAM can be written as:

$$
\begin{aligned}
& g\left(E\left(Y_{i t}\right)\right)=\beta X_{i t}+\sum_{j=1}^{n} \quad f_{j}\left(x_{i}\right) \quad--(5) \\
& Y_{i t}=E\left(Y_{i t}\right)+\epsilon_{i t}
\end{aligned}
$$

Where is a link function, denotes the response variable, the vector contains fixed parameters, is a row of fixed effects matrix and are smoothing splines of the $n$ explanatory covariates, . The residual errors are random Gaussian noise with mean 0 .

Model fitting was done using \%IRI of diatoms, dinoflagellates, copepods, Acetes and tintinnids as independent variables and environmental variables as covariates. Model building was started with a full model that included all environmental variables and meaningful interactions. Afterwards, stepwise forward selection method was implemented to remove nonsignificant variables with the threshold set at $p<0.05$. Adequacy of the models was tested by (1) normal distribution of the residuals (2) homoscedasticity of error variance and (3) non correlated errors. The candidate models were compared by means of Akaike Information Criterion (AIC), R squared statistic, F-statistic and root mean square error values. The best fit model was then selected. An autocorrelation function (ACF) and partial autocorrelation function (PACF) were used to check the independent and random distribution of the residuals over time from the established models. Cross validation of the model was done using $\mathrm{CV}$ gam function of gamclass package in R. Prior to fitting the model, independent variable data (\% IRI) was log transformed and normalized.

\section{Results}

\section{Diet composition}

A total of 120 prey items were encountered. Cumulative prey curve (Fig. 1) of overall diet reached an asymptote after $38 \%$ (480) of the guts were observed, which is approximately half of the total number of guts studied. Among the various prey items observed the different taxa which formed major constituents of the diet of mackerel in the years 2013-2015 were 74 species of diatoms, 16 species of dinoflagellates, 5 species of protozoans, 6 orders of copepods, fish larva and other zooplanktons. The importance of each prey category was estimated by IRI. The most dominant prey items with high frequency of occurrence $(\% 0)$ were diatoms, dinoflagellates, copepods, Acetes and tintinnids. The frequency of occurrence of the prey items were diatoms $36 \%$, dinoflagellates $18 \%$, copepods $13 \%$, Acetes $7 \%$ and protozoans (tintinnids) 5\% (Fig. 2).

The species of diatoms occurring in the diet of $R$. kanagurta were (Fig. 3a) Fragillaria, Nitzchia, Thalassiothrix, Thalassiosira,

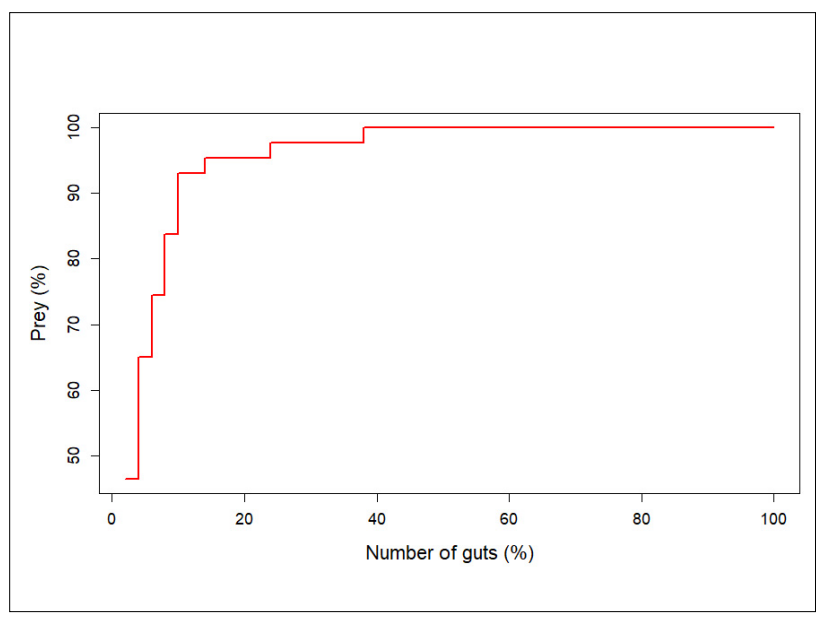

Fig. 1. Cumulative prey percentage curve of Indian mackerel 


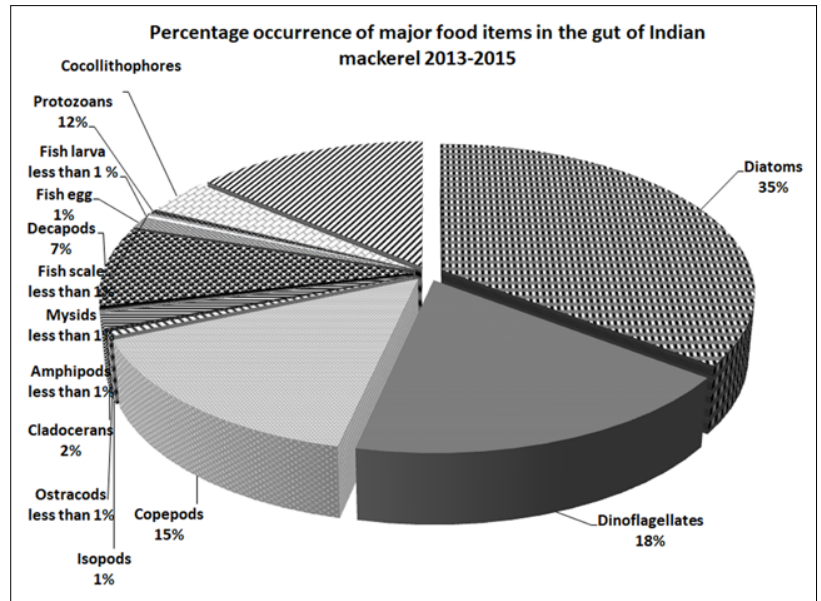

Fig. 2. Percentage occurrence of major prey items in the gut of Indian mackerel during 2013-2015 (pooled)

Coscinodiscus, Rhizosolenia, Pleurosigma, Bidulphia, Chaetoceros, Melosira, Skeletonema, Hemiaulus, Cyclotellla, Ceratulina, Triceratium, Leptocylindrus, Lithodesmium, Asterionella, Lauderia, Thalassionema, Navicula and Gyrosigma. The dinoflagellate species (Fig. 3b) were Ceratium, Ornithocercus, Dinophysis, Protoperidinium, Prorocentrum, Pyrocystis and Pyrophacus. The

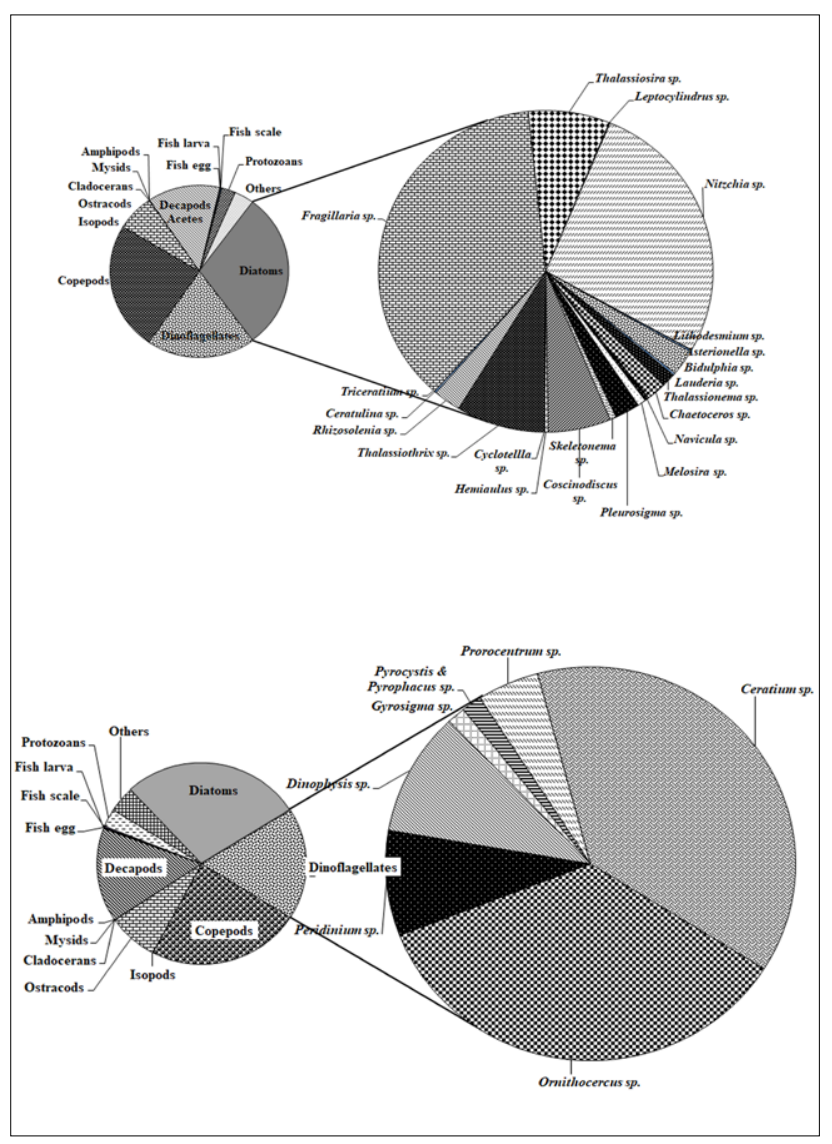

Fig. 3. Percentage IRI of (a) diatoms and (b) dinoflagellates observed in the gut of Indian mackerel
Tintinnid belonged to Tintinnopsis, Codenellopsis and Flavella species. Copepods encountered in the gut belonged to the orders Calanoida, Cyclopoida and Harpacticoida. In addition, Decapods, Isopods and Amphipods were also observed in the gut of the fish.

Comparison of diet composition of different length groups (Fig. 4a, 4b and 4c) by their Index of Relative Importance (\%IRI) demonstrated diatoms, dinoflagellates and copepods as the most common prey item observed in the guts of length groups 110-150 mm. Both fishes of younger and greater stages showed significant \%IRI for diatoms and dinoflagellates in their diet. As the fish progressed to greater lengths above

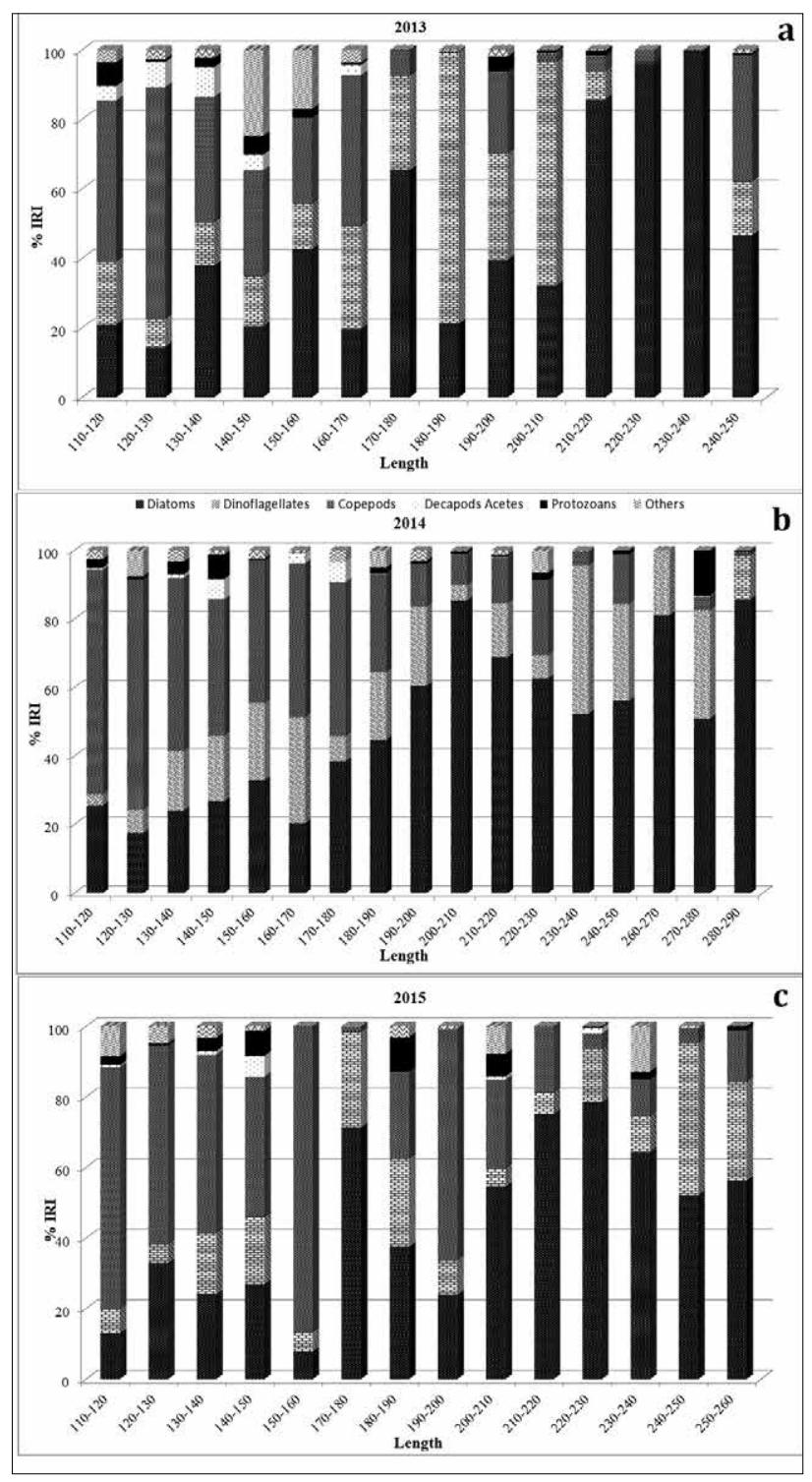

Fig. 4. Length-wise diet composition of (\%IRI) of Indian mackerel - a (2013), b (2014), c (2015) 
$170 \mathrm{~cm}$ the contribution of diatoms in the dietary composition increased with a greater \%IRI value. Decapods, amphipods, isopods and protozoans showed lower relative importance at earlier as well as later stages. All other prey items including fish larvae and eggs occurred in minor quantities in length class above $170 \mathrm{~mm}$ (with \% $\mathrm{IRI}<0.01$ ).

Length-wise (Fig. 5a) and season-wise (Fig. 5b) feeding intensity over three years also revealed that the fish exhibited lower feeding intensities at all stages of their life cycle. Feeding intensity is low in younger stages, gradually increases with length and later reduces as the fish attains maturity. The SST showed a strong positive correlation with the occurrence of PF guts (Fig. 6a) and a strong negative correlation with the occurrence of AF guts (Fig. 6b).

Amundsen plot (Fig. 7a) demonstrated the specialized feeding strategy for Indian mackerel. According to the plot diatoms had high specific abundance and low occurrence whereas copepods and dinoflagellates had low specific abundance and a high occurrence. Other prey items including decapods

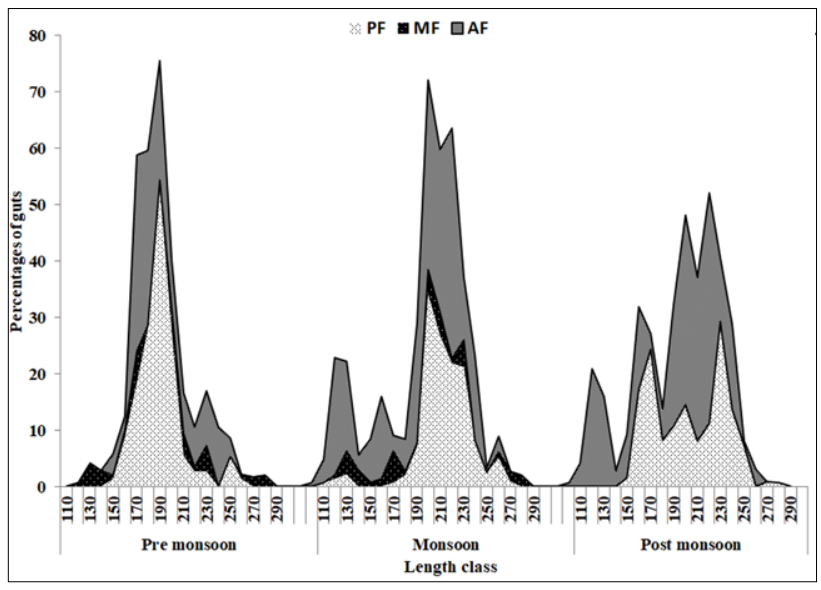

Fig. 5a. Length-wise feeding intensity of Indian mackerel

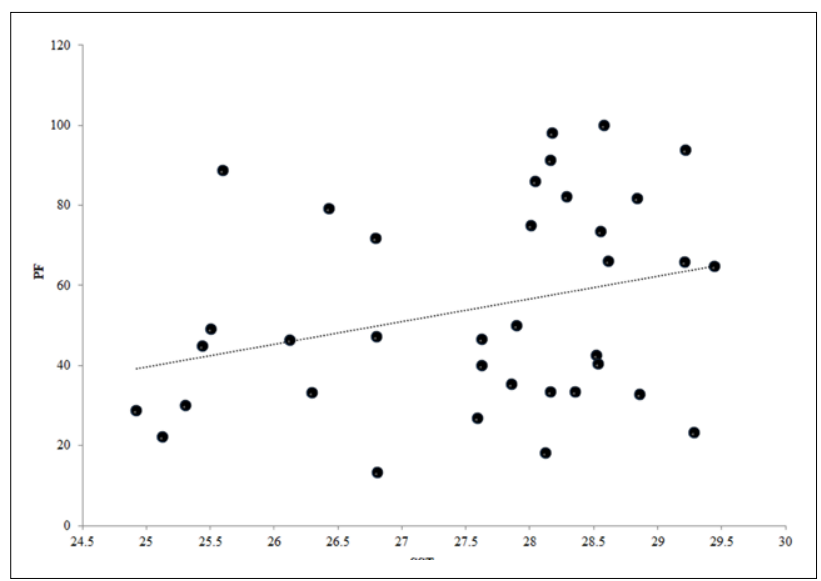

Fig.6a. Correlation between SST and feeding intensity of Indian mackerel for poorly fed guts (PF)
(Acetes), and tintinnids exhibited low prey specific abundance and low occurrence. Since diatoms are positioned in the upper left, they might have been consumed by a few individuals displaying specialization. Dinoflagellates, copepods and tintinnids have been eaten occasionally (generalization). Observations on the trophic levels (Fig. 7b) indicate that young fishes (110-150 mm) feed on higher organisms than older fishes of greater lengths (approximately $>150 \mathrm{~mm}$ ). Thus the results support earlier views that Indian mackerel show specialized feeding habits in different stages of their life cycle.

However, analysis of historical data on the general diet composition as well as seasonal diet composition across all length groups of Indian mackerel from the period 1955 to 2015 revealed a different picture. Though diatoms and copepods show up as major components in the diet, their relative abundance has reduced over the historic period. On the other hand, dinoflagellates, Acetes and protozoans (tintinnids) show an increasing trend in their occurrence in the diet (Fig. 8).

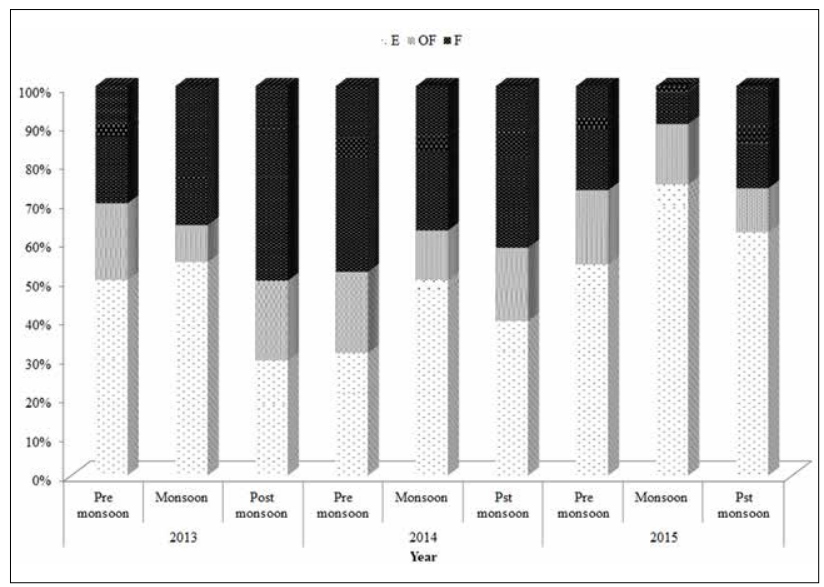

Fig. 5b. Season-wise feeding intensity of Indian mackerel

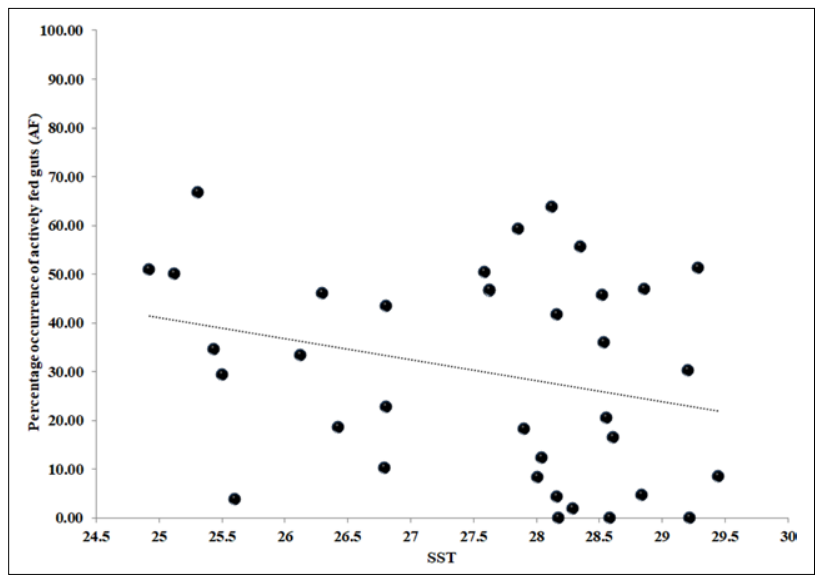

Fig. 6b. Correlation between SST and feeding intensity of Indian mackerel for actively fed guts (AF) 


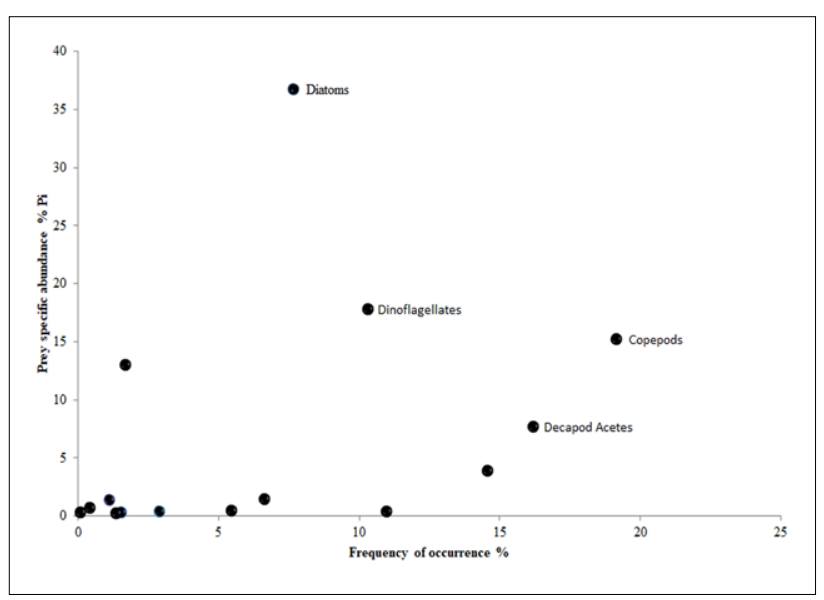

Fig. 7a. Amundsen plot depicting feeding strategy of Indian mackerel

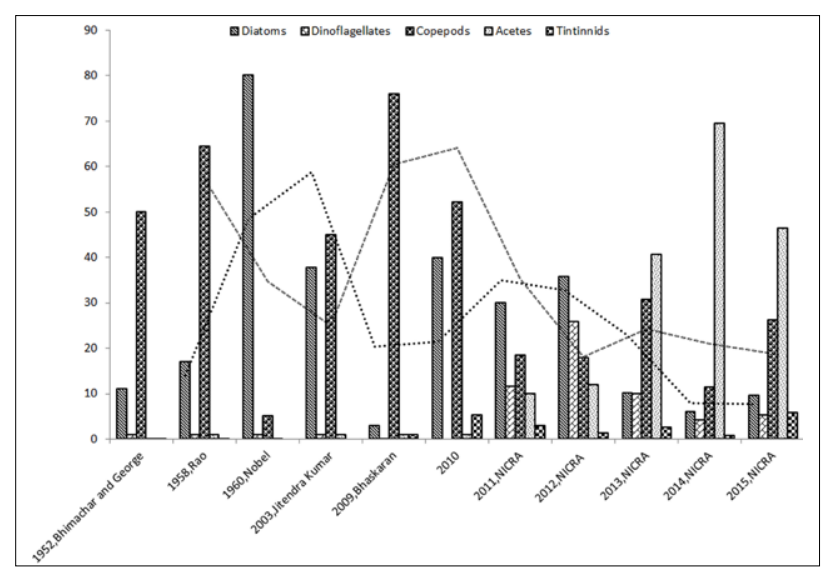

Fig. 8. Shift in diet components of Indian mackerel from historic to recent period

\section{Diatoms and dinoflagellates}

The GAM model fitted (Fig. 9) to examine whether any nonlinear relationship exists with predictor (environmental variables) and response or covariates (IRI of prey items in the gut of mackerel) showed highly significant results. The best fit model for diatoms was obtained with SST, Pr, Chl $a$ and CUI (Table 1). Temperatures lower than $27^{\circ} \mathrm{C}$ accounted for guts with greater relative importance for diatoms. As the temperature increased the relative importance of diatoms in the gut decreased (Fig. 9a (i)). The relationship of the relative importance of diatoms in the gut with Pr was a little wiggly which shows the high sensitiveness of diatoms to Pr. The model explains gradual increasing effect Pr with the diatoms in the gut (Fig. 9a (ii)). Chl a concentration (Fig. 9a (iii)) and CUI (Fig. 9a (iv)) was linearly associated with diatoms in the diet showing a steep increase. From the output it is clear that the occurrence of diatoms in the diet is influenced by SST, $\mathrm{Pr}, \mathrm{Chl} a$ and CUI and the relationship is statistically significant.

The fitted functions of GAM model demonstrate (Table 1) the

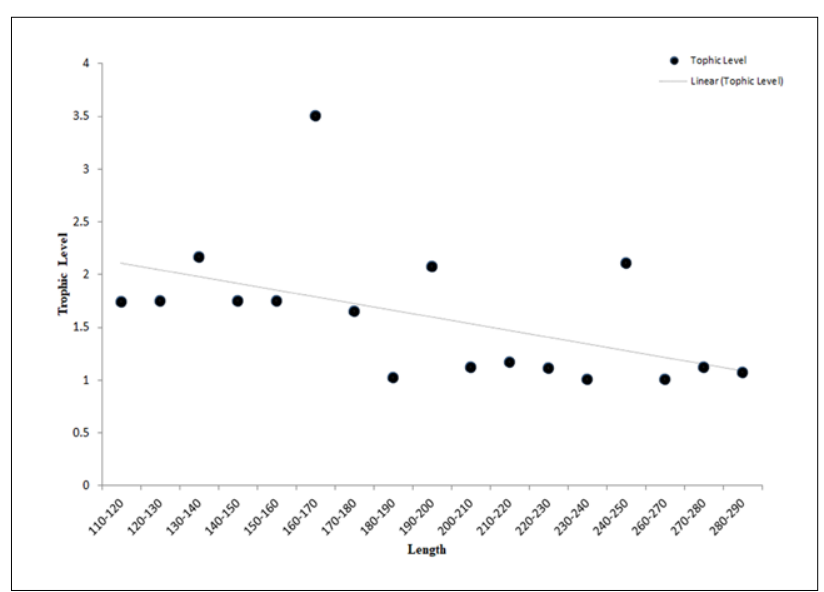

Fig. 7b. Length-wise Trophic level of Indian mackerel

strong association of the relative importance of dinoflagellates with SST, Pr, CUI and salinity. Their relative importance in the diet remains almost same even as the SST increases (Fig. $9 \mathrm{~b}$ (i)). Low and moderate Pr has a decreasing effect on the occurrence of dinoflagellates. High Pr above $6 \mathrm{~mm} /$ day showed an increasing effect in their relative importance (Fig. 9b (ii)). The association of CUI to dinoflagellates was very wiggly (Fig. 9b (iii)), whereas with increase in salinity the occurrence of dinoflagellates in the gut decreased steadily (Fig. 9b (iv)).

\section{Copepods, Acetes and tintinnids}

GAM results showing association between copepods in the gut and covariates is shown in Fig. 9c. From the output it is clearly evident that SST above $28^{\circ} \mathrm{C}$ shows a decreasing effect (Fig. 9c (i)), whereas with $\mathrm{Chl} a$, the relationship is very sensitive with a positive effect (Fig. 9c (ii)). On the contrary, increase in salinity above 32 psu has a negative effect (Fig. 9c (iv)) in the relative importance of copepods in the gut.

Other prey items encountered in the study which showed an increase in their presence in the diet of mackerel over historic period were Acetes and tintinnids. According to the model output (Fig. 9d) tintinnids are most affected by SST, Chl a, CUI and salinity, whereas the IRI of Acetes showed an association with SST, Pr and salinity. Gut having

Table 1. Selected GAM models showing relationship between prey components $(\% \mathrm{II})$ in the diet of Indian mackerel and environmental variables

\begin{tabular}{|c|c|c|}
\hline Model & Dev. $(\%)$ & Adj. $R$ \\
\hline Diatoms $\sim \mathrm{s}(\mathrm{SST})+\mathrm{s}(\mathrm{Pr})+\mathrm{s}(\mathrm{Chl} a)+\mathrm{s}(\mathrm{CUI})$ & 63.90 & 0.49 \\
\hline Dinoflagellates $\sim \mathrm{s}(\mathrm{SST})+\mathrm{s}(\mathrm{Pr})+\mathrm{s}($ salinity $)+\mathrm{s}(\mathrm{CUI})$ & 95 & 0.863 \\
\hline Copepods $\sim \mathrm{s}(\mathrm{SST})+\mathrm{s}$ (salinity) $+\mathrm{s}(\mathrm{Chl} a)$ & 51.50 & 0.459 \\
\hline Acetes $\sim \mathrm{s}(\mathrm{SST})+\mathrm{s}(\mathrm{Pr})+\mathrm{s}($ salinity $)$ & 84.40 & 0.72 \\
\hline Tintinnids $\sim s($ SST $)+s(C U I)+s(C h l a)+s($ salinity $)$ & 91.1 & 0.762 \\
\hline
\end{tabular}




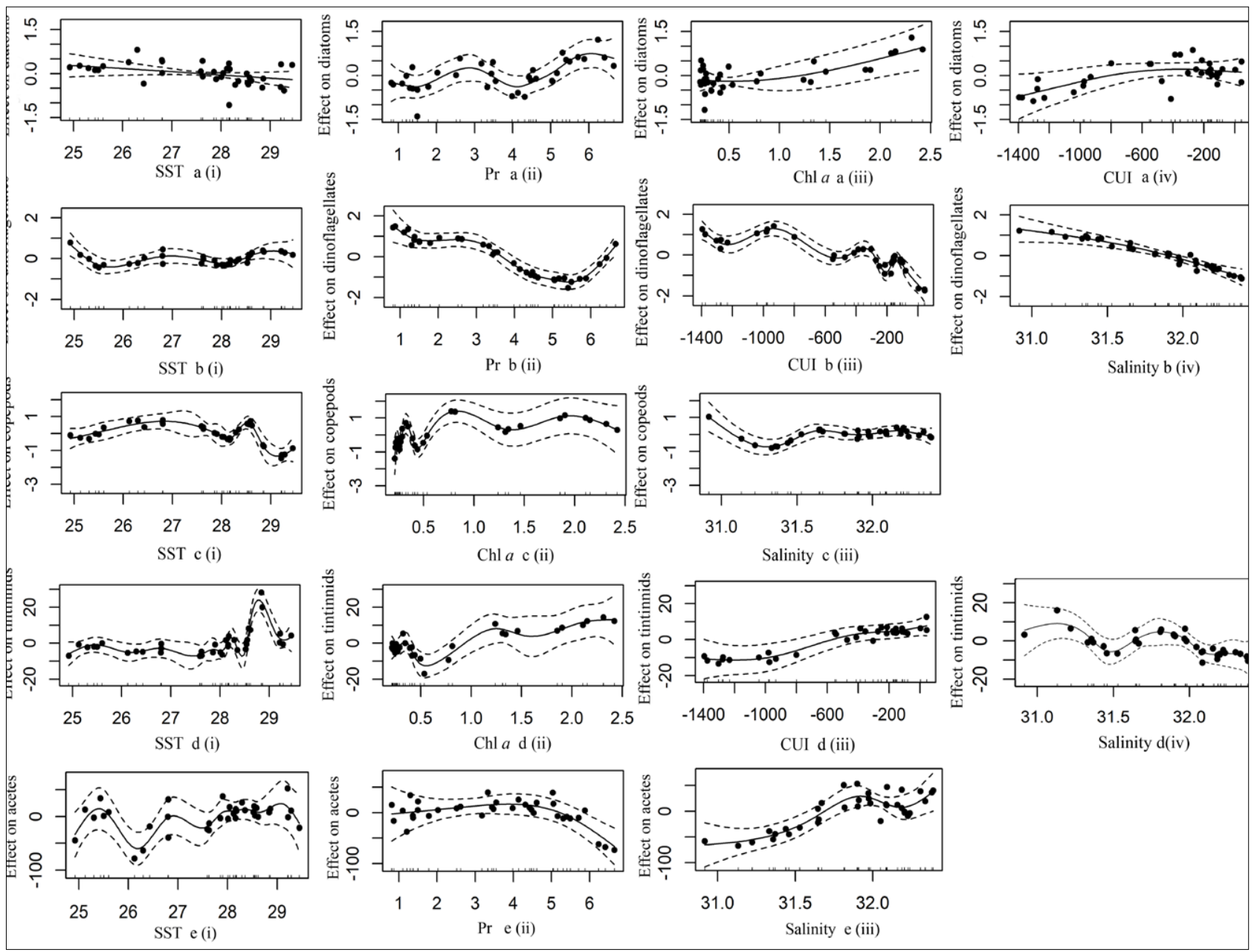

Fig. 9. GAM plots showing relationship between environmental variables and \% IRI of (a) diatoms (b) dinoflagellates (c) copepods (d) tintinnids and (e) Acetes

greater relative importance for tintinnids can be seen at temperatures higher than $28^{\circ} \mathrm{C}$ (Fig. 9d (i)). Increase in Chl a concentration (Fig. 9d (ii)) and positive Ekman transport (upwelling) (Fig. 9d (iii)) showed an increasing effect on the occurrence of tintinnids in the diet. Salinity was not found to have significant negative effect on the occurrence of tintinnids in the diet (Fig. 9d (iv)).

An increase in the relative importance of Acetes can be seen
Table 2. Approximate significance of smooth terms (GAM model of diatoms and dinoflagellates)

\begin{tabular}{lllllll}
\hline \multicolumn{3}{c}{ Variable } & \multicolumn{3}{c}{ diatoms } & \multicolumn{2}{c}{ dinoflagellates } \\
\hline & edf & F & p value & edf & $F$ & $p$ value \\
\hline s (SST) & 1.4276 & 0.777 & 0.04842 & 6.367 & 2.451 & $0.00857^{\star *}$ \\
\hline s (Pr) & 6.0978 & 1.887 & 0.00581 & 6.174 & 13.416 & $1.64 \mathrm{e}-08^{\star * *}$ \\
\hline s (Chla) & 0.6843 & 4.5 & 0.00321 & - & - & - \\
\hline s (salinity) & - & - & - & 1.847 & 19.708 & $5.14 \mathrm{e}-06^{\text {***}}$ \\
\hline s (CUI) & 2.0415 & 0.471 & 0.04592 & 7.992 & 10.863 & $4.18 \mathrm{e}-06^{\text {***}}$ \\
\hline
\end{tabular}

Table 3. Approximate significance of smooth terms (GAM model of copepods, Acetes and tintinnids)

\begin{tabular}{|c|c|c|c|c|c|c|c|c|c|}
\hline \multirow[t]{2}{*}{ Variable } & \multicolumn{4}{|c|}{ copepods } & \multicolumn{2}{|c|}{ Acetes } & \multicolumn{3}{|c|}{ tintinnids } \\
\hline & edf & $\mathrm{F}$ & $p$ value & edf & $\mathrm{F}$ & $p$ value & edf & $\mathrm{F}$ & $p$ value \\
\hline$S(S S T)$ & 1.5247 & 4.942 & $0.00382^{\star \star}$ & 8.344 & 3.419 & $0.001435^{\star \star}$ & 10.944 & 15.393 & $6.96 \mathrm{e}-07^{\star * *}$ \\
\hline $\mathrm{S}(\mathrm{Pr})$ & _- & _- & - & 3.437 & 4.864 & $0.000102^{\star \star *}$ & - & - & - \\
\hline s (Chla) & 1.034 & 3.331 & $0.00138^{\star \star}$ & - & - & - & 3.982 & 6.734 & $0.00187^{* *}$ \\
\hline s (salinity) & 0.9999 & 3.031 & $0.0014^{* \star}$ & 3.723 & 9.826 & $1.87 \mathrm{e}-05^{\star \star \star}$ & 10.489 & 5.071 & 0.00739 ** \\
\hline $\mathrm{s}(\mathrm{CUI})$ & - & _ & _ & - & - & - & 1.284 & 0.812 & 0.07085 \\
\hline
\end{tabular}


with increase in SST (above $29^{\circ} \mathrm{C}$ ) and salinity (above 31 psu). Increase in Pr over $5 \mathrm{~mm} /$ day had a decreasing effect on the occurrence of guts with greater IRI for Acetes (Fig. 9e). The significance of smooth terms is shown in Table 2 and Table 3.

\section{Discussion}

Historical and seasonal analysis of diet composition data show that the role of environmental conditions cannot be simply ruled out and therefore changes in the diet composition may not be attributed to be the consequence of ontogeny alone. Abiotic environment (Sotka and Giddens, 2009), food quality (Behrens and Lafferty, 2007) and prey availability (Dörner et al., 2003) has been reported to play significant role in the diet composition of fishes. Thus the fluctuation in diet composition in three years as well as the historic period may also be attributed to the changes in the availability of prey (planktons) in the sea in response to the changing climatic conditions.

When considering the general diet composition of all length groups during the study period, it can be observed that phytoplanktons are increasing in the diet. The gradual reduction in the occurrence of diatoms and increase in the occurrence of dinoflagellates (Fig. 3) composing the phytoplanktivorous diet may be due to the changes in their abundance, in response to change in environmental variables such as SST, salinity, $\mathrm{Pr}$ and upwelling (Hinder et al., 2012). In concurrence with this it was observed that the feeding intensity of the fish was also strongly related to the SST. Younger stages in which the diet is expected to be mainly composed of zooplanktons, also showed high relative importance of phytoplanktons. The increased occurrence of phytoplanktons in the diet in younger stages can be explained as a negative impact of higher sea water temperature which favours tropical pelagic fishes to select herbivory against omnivory and carnivory (Beherens and Lafferty, 2007). These observations are supported by earlier studies that reports trophic mismatch exhibited by the pelagic community in response to pulsed planktonic production (Edwards and Richardson, 2004), due to their evolved ability to survive on a low-quality diet (Harmelin-Vivien, 2002). These results also support the view that mackerel is an opportunistic feeder (Supraba et al., 2016).

Theoretical evidences support the GAM model results that explain relationships between the diet components and environmental variables. Linear association of $\mathrm{Chl}$ a concentration with increased IRI of diatoms in the gut strongly suggests that it has a significant association with chlorophyll abundance in the environment. Several studies have reported the reduction in the abundance of diatoms in the tropics due to their high sensitivity to increase in SST (Edwards and Richardson, 2004, Thomas et al., 2012), salinity (Rai and Rajashekhar, 2014) and $\operatorname{Pr}$ (Chen et al., 2016).
On contrary, dinoflagellates are well adapted to the increasing temperatures which is associated with changes in $\mathrm{Pr}$, increased thermal stratification and nutrients loads (Golubkov et al., 2019). Salinity also has been reported to be a major factor influencing dinoflagellate assemblages in many regions (Price et al., 2017). A switchover in the dominant species of winter phytoplankton communities from diatoms to dinoflagellates in the Arabian Sea has been reported by Gomes et al. (2008).

Copepod abundance in the gut has decreased from 1952 to 2015 whereas the occurrence of Acetes and tintinnids (protozoans) show an increase (in their relative importance) in the diet. In addition, copepods also show reduction in their relative importance with increase in SST (above $28^{\circ} \mathrm{C}$ ) and salinity (>31 psu) during the investigation period. This may be due to the negative influence of increasing temperature and salinity on the distribution of copepods (Gorokhova et al., 2013). Strong association of copepods with $\mathrm{Chl} a$ in the environment may be due to the fact that they are directly linked to the abundance of diatoms in the environment as shown by the studies of Richardson and Schoeman (2004). Relative importance of tintinnids in the gut are observed to increase with increasing temperature to a maximum, before declining near $30^{\circ} \mathrm{C}$, which may be due to the fact they are more adapted to increasing temperature. Similarly upwelling, salinity (Laybourn-Parry, 1992) and availability of diatoms as food (Tiffany et al., 2007) affect the growth and proliferation of tintinnids. Abundance of Acetes is strongly related to heavy rainfall, water temperature (Chiou et al., 2000) and salinity (Metillo, 2011, Simoes et al., 2013). Evidences also support the assumption that climate-mediated biogeographical shifts in copepod blooms has occurred in the seas (Beaugrand et al., 2002). Variations in the density of copepods and Acetes along southern Kerala coast as a result of changes in the marine environment have been reported by Robin et al. (2009). All these support the hypothesis that the prey items encountered in the gut of Indian mackerel have a strong relationship with their abundance in the environment which in turn is affected by the changing climatic conditions.

Changes in the prey preference of Indian mackerel is also supported by the study of Smith et al. (2008) which states that climate change affects not only the abundance and growth rate of phytoplankton but also shifts the type of species present in the environment, with bottom up effects in the food web. Nevertheless, changes in the synchrony between peak in plankton abundance and arrival of fish larva can also affect larval growth, survival and recruitment of the fish and thereby the fishery of the Indian mackerel.

From the current investigation it is clearly evident that climate change driven shifts in the abundance of marine planktons affects the relative importance of various prey items in the diet 
of Indian mackerel. The study also shows that mackerel is an opportunistic feeder which feeds on the available prey items in the environment. The changes in the diet composition of Indian mackerel can be considered as an indication of the changes in the abundance of prey items in their potential habitat which can also be considered as an indicator of climate change.

\section{Acknowledgements}

We express our sincere gratitude to the Indian Council of Agricultural Research (ICAR) for providing financial support for the study through the National Innovations in Climate Resilient Agriculture (NICRA) project implemented at CMFRI. We are also grateful to the Director, ICAR-CMFRI for providing facilities for carrying out the study.

\section{References}

Abdussamad, E. M., N. G. K. Pillai, H. M. Kasim and O. M. M. J. Mohamed. 2010. Fishery, biology and population characteristics of the Indian mackerel, Rastrelliger kanagurta (Cuvier) exploited along the Tuticorin coast. Indian J. Fish., 57(1): $17-21$

Amundsen, P. A., H. M. Gabler and F. J. Staldvik. 1996. A new approach to graphical analysis of feeding strategy from stomach contents data - modification of the Costello (1990) method. J. Fish. Biol., 48: 607-614.

Beaugrand, G., P. C. Reid, F. Ibanez, J. A. Lindley and M. Edwards. 2002. Reorganization of North Atlantic marine copepod biodiversity and climate. Science, 296(5573): 1692-1694.

Behrens, M. D. and K. Lafferty. 2007. Temperature and diet effects on omnivorous fish performance: implications for the latitudinal diversity gradient in herbivorous fishes. Canadian J. Fish. Aquat. Sci., 64(6): 867-873.

Chen, X., W. Zhou, S. T. Pickett, W. Li, L. Han and Y. Ren. 2016. Diatoms are better indicators of urban stream conditions: a case study in Beijing, China. Ecol. Indic., 60: 265-274.

Chiou, W. D., C. C. Wu and L. Z. Cheng. 2000. Spatiotemporal distribution of sergestid shrimp Acetes intermedius in the coastal waters of southwestern Taiwan. Fish. Sci., 66(6): 1014-1025.

CMFRI. 2018. Annual Report 2017-18. Central Marine Fisheries Research Institute, Kochi, 292 pp.

Coupled Model Intercomparison Project (CMIP5), Lawrence Livermore National Laboratory, 2017. https://st.IInl.gov/

Dörner, H., S. Berg, L. Jacobsen, S. Hülsmann, M. Brojerg and A. Wagner. 2003. The feeding behaviour of large perch Perca fluviatilis (L.) in relation to food availability: a comparative study. Hydrobiologia, 506(1-3): 427-434.

Edwards, M. and A. J. Richardson. 2004. Impact of climate change on marine pelagic phenology and trophic mismatch. Nature, 430 (7002): 881.

Golubkov, M., V. Nikulina and S. Golubkov. 2019. Effects of environmental variables on midsummer dinoflagellate community in the Neva Estuary (Baltic Sea). Oceanologia, 61(2): 197-207.

Gomes, H. D. R., J. I. Goes, S. G. P. Matondkar, S. G. Parab, A. R. N. Al-Azri and P. G. Thoppil. 2008. Blooms of Noctiluca miliaris in the Arabian Sea - An in situ and satellite study. Deep-Sea Res., (1 Oceanogr. Res. Pap.), 55(6): 751-765.

Gorokhova, E., M. Lehtiniemi, J. Lesutiene, S. Strake, L. Uusitalo, N. Demereckiene and C. Amid. 2013. Zooplankton mean size and total abundance. HELCOM Core Indicator Report Online. HELCOM (2013). 7 pp.

Harley, C. D., A. R. Hughes, K. M. Hultgren, B. G. Miner, C. J. Sorte, C. S. Thornber, L. F. Rodriguez, L. Tomanek and S. L. Williams. 2006. Erratum: The impacts of climate change in coastal marine systems. Ecol. Lett., 9(4): 500
Harmelin-Vivien, M. L. 2002. Energetics and fish diversity on coral reefs. In: P.F. Sale (Eds.) Coral reef fishes: dynamics and diversity in a complex ecosystem, Academic, San Diego, p. 265 - 274.

Hastie, T. and R. Tibshirani. 1990. Exploring the nature of covariate effects in the proportional hazards model. Biometrics, 46(4): 1005-16.

Hinder, S. L., G. C. Hays, M. Edwards, E. C. Roberts, A. W. Walne and M. B. Gravenor 2012. Changes in marine Dinoflagellate and diatom abundance under climate change. Nat. Clim. Change, 2(4): 271

International Comprehensive Ocean-Atmosphere Data set (ICOADS), 2018. http:// icoads.noaa.gov/publications.html

IPCC, 2007: Climate Change 2007: The Physical Science Basis. Contribution of Working Group I to the Fourth Assessment Report of the Intergovernmental Panel on Climate Change. In: S. Solomon, D. Qin, M. Manning, Z. Chen, M. Marquis, K. B. Averyt, M. Tignor and H. L. Miller (Eds.). Cambridge University Press, Cambridge, United Kingdom and New York, NY, USA, 996 pp.

Laybourn Parry, J. 1992. Protozoan Plankton Ecology. Chapman and Hall, New York, $231 \mathrm{pp}$.

Metillo, E. B. 2011. Feeding Ecology of Acetes intermedius Omori 1975 (Crustacea, Decapoda, Sergestidae) in Iligan Bay, the Philippines. Zool. Stud., 50(6): 725-736.

NASA Godard Space Flight Center, Sea-Data Analysis Center, 2017. https://seadas.gsfc. nasa.gov/

National Oceanic and Atmospheric Administration Earth System Research Laboratory, 2018. https://www.esrl.noaa.gov/about/organization.html

Pauly, D., A. W. Trites, E. Capuli and V. Christensen. 1998. Diet composition and trophic levels of marine mammals. ICES J. Mar. Sci., 55(3): 467-481.

Pinkas, L., M. S. Oliphant and I. L. K. Inverson. 1971. Food habits of albacore, bluefin tuna, and bonito in Californian waters. Fish. Bull., 152: 11 - 105

Price, A. M., M. R. Coffin, V. Pospelova, J. S. Latimer and G. L. Chmura. 2017. Effect of nutrient pollution on Dinoflagellate cyst assemblages across estuaries of the NW Atlantic. Mar. Pollut. Bull., 121(1-2): 339-351.

Rai, S. V. and M. Rajashekhar. 2014. Seasonal assessment of hydrographic variables and phytoplankton community in the Arabian Sea waters of Kerala, southwest coast of India. Brazilian J. Oceanogr., 62(4): 279-289.

Rao, K. V. 1964. Distribution of the young stages of the mackerel, Rastrelliger kanagurta (Cuvier) in the Indian inshore waters. In: E. G. Silas (Eds.), Proceedings of the Symposium on Scombroid Fishes, Part 1, Marine Biological Association of India, Mandapam Camp. p. 469 - 482.

Richardson, A. J. and D. S. Schoeman. 2004. Climate impact on plankton ecosystems in the Northeast Atlantic. Science, 305: 1609 - 1612.

Robin, R. S., M. Srinivasan and K. Chandrasekhar. 2009. Distribution of zooplankton from Arabian Sea along southern Kerala (south west coast of India) during the Cruise. Curr. Res. J. Biol. Sci., 1(3): 155 - 159.

Simoes, S. M., A. L. Castilho, A. Fransozo, M. L. Negreiros-Fransozo and R. C. da Costa. 2013. Distribution related to temperature and salinity of the shrimps Acetes americanus and Peisos petrunkevitchi (Crustacea: Sergestoidea) in the southeastern Brazilian littoral zone. J. Mar. Biol. Ass. UK, 93: 753-759.

Sivadas, M. and M. M. Bhaskaran. 2009. Stomach content analysis of the Indian mackerel Rastrelliger kanagurta (Cuvier) from Calicut, Kerala. Indian J. Fish., 56(2): 143-146.

Smith, W., D. Steinberg, D. Bronk and M. Tang. 2008. Marine plankton food webs and climate change. http:// estuaries.noaa.gov/teachers/pdf/Plankton_Food_Webs_ VIMS.pdf, 4 pp.

Sotka, E. E. and H. Giddens. 2009. Seawater temperature alters feeding discrimination by cold-temperate but not subtropical individuals of an ectothermic herbivore. Biol. Bull., 216(1): 75-84.

Supraba, V., A. P. Dineshbabu, T. Sujitha, R. Pratibha and K. M. Rajesh. 2016. Climate influence on oil sardine and Indian mackerel in Southeastern Arabian Sea. Int. J. Dev. Res., 6(8): 9152-9159.

Thomas, M. K., C. T. Kremer, C. A. Klausmeier and E. Litchman. 2012. A global pattern of thermal adaptation in marine phytoplankton. Science, 338(6110): 1085-1088.

Tiffany, M. A., M. R. González, B. K. Swan, K. M. Reifel, J. M. Watts and S. H. Hurlbert. 2007. Phytoplankton dynamics in the Salton Sea, California, 1997 - 1999. Lake Reserv. Manage., 23(5): 582-605. 